\title{
Etiology and Risk Factors of Acute Gastroenteritis in a Taipei Emergency Department: Clinical Features for Bacterial Gastroenteritis
}

\author{
Chao-Chih Lai ${ }^{1,2}$, Dar-Der $\mathrm{Ji}^{3,6}$, Fang-Tzy $\mathrm{Wu}^{3}$, Jung-Jung $\mathrm{Mu}^{3}$, Ji-Rong Yang $^{3}$, \\ Donald Dah-Shyong Jiang ${ }^{4}$, Wen-Yun Lin ${ }^{1}$, Wei-Ting Chen ${ }^{1}$, Muh-Yong Yen ${ }^{5}$, \\ Ho-Sheng $\mathrm{Wu}^{3}$, and Tony Hsiu-Hsi Chen ${ }^{2}$ \\ ${ }^{1}$ Emergency Department, Taipei City Hospital, Ren-Ai Branch, Taipei, Taiwan \\ ${ }^{2}$ Graduate Institute of Epidemiology and Preventive Medicine, College of Public Health, National Taiwan University, \\ Division Biostatistics, Taipei, Taiwan \\ ${ }^{3}$ Research and Diagnostic Center, Centers for Disease Control, Department of Health, Taipei, Taiwan \\ ${ }^{4}$ Field Epidemiology Training Program, Centers for Disease Control, Taipei, Taiwan \\ ${ }^{5}$ Infectious Disease Section, Taipei City Hospital, Taipei, Taiwan \\ ${ }^{6}$ Department of Tropical Medicine, National Yang-Ming University, Taipei, Taiwan
}

Received March 4, 2015; accepted July 20, 2015; released online December 5, 2015

Copyright (C) 2015 Chao-Chih Lai et al. This is an open access article distributed under the terms of Creative Commons Attribution License, which permits unrestricted use, distribution, and reproduction in any medium, provided the original author and source are credited.

\section{ABSTRACT}

Background: The causative pathogen is rarely identified in the emergency department (ED), since the results of cultures are usually unavailable. As a result, antimicrobial treatment may be overused. The aim of our study was to investigate the pathogens, risk factors of acute gastroenteritis, and predictors of acute bacterial gastroenteritis in the ED.

Methods: We conducted a matched case-control study of 627 stool samples and 612 matched pairs.

Results: Viruses (41.3\%) were the leading cause of gastroenteritis, with noroviruses (32.2\%) being the most prevalent, followed by bacteria (26.8\%) and Giardia lamblia (12.4\%). Taking antacids (adjusted odds ratio [aOR] 4.10; 95\% confidence interval [CI], 2.57-6.53), household members/classmates with gastroenteritis (aOR 4.69; 95\% CI, 2.76-7.96), attending a banquet (aOR 2.29; 95\% CI, 1.64-3.20), dining out (aOR 1.70; 95\% CI, 1.13-2.54), and eating raw oysters (aOR 3.10; 95\% CI, 1.61-5.94) were highly associated with gastroenteritis. Elders (aOR 1.04; 05\% CI, 1.02-1.05), those with CRP $>10 \mathrm{mg} / \mathrm{L}$ (aOR 2.04; 95\% CI, 1.15-3.62), or those who were positive for fecal leukocytes (aOR 2.04; 95\% CI, 1.15-3.62) or fecal occult blood (aOR 1.97; 95\% CI, 1.03-3.77) were more likely to be hospitalized in ED. In addition, presence of fecal leukocytes (time ratio [TR] 1.22; 95\% CI, 1.06-1.41), abdominal pain (TR 1.20; 95\% CI, 1.07-1.41), and frequency of vomiting (TR 0.79; 95\% CI, 0.64-0.98) were significantly associated with the duration of acute gastroenteritis. Presence of fecal leukocytes (aOR 2.08; 95\% CI, 1.42-3.05), winter season (aOR $0.45 ; 95 \%$ CI, 0.28-0.74), frequency of diarrhea (aOR 1.69; 95\% CI, 1.01-2.83), and eating shrimp or crab (aOR $1.53 ; 95 \%$ CI, 1.05-2.23) were highly associated with bacterial gastroenteritis. The area under the receiver operating characteristic curve of the final model was 0.68 (95\% CI, 0.55-0.63).

Conclusions: Acute bacterial gastroenteritis was highly associated with season, frequency of diarrhea, frequency of vomiting, and eating shrimp or crab.

Key words: acute gastroenteritis; fecal leukocytes; fecal occult blood; norovirus; salmonella; Giardia lamblia; receiver operating characteristic; $\mathrm{C}$-reactive protein

\section{INTRODUCTION}

Acute gastroenteritis is a common disease in the emergency department (ED). Viruses are the leading cause of acute gastroenteritis presenting to the ED. ${ }^{1}$ Most cases of acute gastroenteritis are self-limiting, but some patients with more serious infection resulting from invasive bacterial and parasitic organisms may present with life-threatening 
dehydration and shock. The epidemiologic settings and clinical and laboratory features that are associated with acute gastroenteritis influence the probability of each pathogen. $^{2}$ The causative pathogens are rarely identified in the ED because the results of cultures are usually unavailable due to time constraints or failure to obtain specimens. ${ }^{3}$ Nonetheless, antimicrobial treatment is still indispensable in patients with suspected invasive diarrhea, which is marked by the presence of fever, abdominal pain, fecal leukocytes, and hemoccult. However, clinical features of invasive diarrhea also present in cases of viral gastroenteritis, so antimicrobial treatment may be overused in the ED. Research on using clinical attributes to identify the cause of acute gastroenteritis in the ED is still limited. The aims of the present study were to investigate the pathogens and risk factors of acute gastroenteritis cases presenting to the ED, factors affecting the odds for admission, and the criteria for ancillary testing to diagnose bacterial gastroenteritis.

\section{METHODS}

\section{Study design}

A matched case-control study was conducted in in the ED of Ren-Ai branch of Taipei City Hospital. Data on 754 patients were collected from August 1, 2005, to July 31, 2009. Inclusion criteria for cases were: at least three loose stools or three instances of vomiting; or either diarrhea and/or vomiting plus two or more additional symptoms, including abdominal pain, fever, nausea, blood in the stool, or stool mucus. We excluded patients who were less than 15 years old; exhibited coughing, a sore throat, or runny nose; or were bedridden (defined as anyone who needs help to leave the bed). ${ }^{1}$ Each case patient was matched one-to-one with a nongastroenteritis control patient of the same gender, age (within 5 years), and date of ED visit (within 1 month). If several control patients appeared for one case patient, the one admitted on the date nearest to the case's ED visit date was selected. If the selected control refused to participate, we chose the non-gastroenteritis patient with the next nearest admission date to that of the case's ED visit as the matched control. We followed this protocol until we found a matched control for each case.

We sent questionnaires to all participants after they gave consent to participate in the study. Socio-demographic information, clinical history of gastroenteritis, and factors responsible for the disease, such as consumption of food items, water, and beverages, dining location, travel history, contact with ill persons, contact with animals, habits, medications taken, and previous morbidity, were collected in the questionnaires (see eQuestionnaires). A case-case study was also used to determine the risk factors for admission, the duration of illness, and the predictor of bacterial gastroenteritis. Patients with bacterial gastroenteritis are defined as any positive results of stool culture or polymerase chain reaction (PCR) for bacteria, whether or not patients were positive for other pathogens.

We assumed that the estimated odds ratio was $1.29(0.45 /$ $0.35)$, respectively. A two-sided McNemar test for no effect with a significance level of 0.05 was considered to indicate statistical significance. Hence, a sample size of 626 matched pairs was required.

\section{Specimen collection and laboratory methods}

A total of 627 stool samples were collected immediately after visiting the ED or within 3 days after discharge. Follow-up telephone interviews with all participants were conducted 7-10 days after the ED visit. Blood cultures were performed for patients with fevers. All specimens were sent to the Centers for Disease Control, Taiwan and were analyzed for viruses, parasites, and bacteria. ${ }^{1}$ In this study, the newly developed PCR assays for detecting B. fragilis and $C$. difficile were performed. ${ }^{4}$

All blood tests (including blood cultures) and tests for fecal leukocytes and fecal occult blood were performed at the Taipei City Hospital laboratory. ${ }^{1}$ The threshold for positive fecal leukocytes was defined as more than 1 cell/high-power field (HPF), and fecal occult blood test was assessed using o-tolidine.

\section{Statistical analysis}

Returned questionnaires were coded, and data were entered into Epi Info (version 3.43; U.S. Centers for Disease Control and Prevention, Atlanta, GA, USA) and analyzed using SAS software (release 9.3; SAS Institute Inc., Cary, NC, USA). Chi-square test or Fisher exact test were used for categorical data, and $t$-test or ANOVA were used for continuous data. Medians were compared using the Wilcoxon rank-sum test.

We estimated odds ratios (ORs) and 95\% confidence intervals (CIs) using conditional logistic regression. Conditional logistic regression model with a stepwise selection procedure ( $P$ to enter $<0.10 ; P$ to remove $>0.05$ ) was used to identify the most important determining factors for acute gastroenteritis.

In the case-case study, we estimated ORs and 95\% CIs using the logistic regression model with a stepwise selection procedure (enter: $P<0.10$; remove: $P>0.05$ ) to identify the most important determining factors for admission and predictors of bacterial gastroenteritis. The duration of illness, from the onset of symptoms to the final resolution of symptoms, was evaluated using an accelerated failure time (AFT) model with a Weibull distribution. Parameter coefficients connected with the AFT model were reported as time ratio $\left(\mathrm{TR} ; \mathrm{e}^{\beta}\right)$ in illness duration, a TR $>1$ is associated with a prolonged survival time, whereas a TR $<1$ is associated with a decrease in survival time. The AFT model, a parametric approach, can estimate the baseline hazard, which cannot be obtained with the Cox proportional hazards regression. Therefore, the AFT model is useful for analysis of time to 
event (the duration of illness). The AFT formulation allows the derivation of a time ratio, which is easier to interpret than the Cox proportional hazards regression model. ${ }^{5}$ In addition, the AFT model does not need the assumption of proportional hazards and provides more precise results in the analysis of censored data compared with the Cox proportional hazards regression model.

For comparison of the discriminatory capability of fecal leukocyte testing and the final model, a summary receiver operating characteristic (ROC) curve was constructed. A summary ROC curve was plotted to present the true-positive rate (sensitivity) against the false-positive rate (1specificity). ${ }^{6}$ Calculation of the area under the ROC curve (AUROC) provides a tool for comparison of the discriminatory capacity of different ancillary tests and risk factors.

\section{Ethics}

The study was approved by the Taipei City Hospital Institutional Review Board.

\section{RESULTS}

Of 2341 patients with gastroenteritis during the study period, only $754(32.2 \%)$ patients participated in our study. Among the 754 patients who met the study criteria and returned completed and usable questionnaires, 627 stool samples were collected. There were no significant differences between participants and non-participants in terms of age, gender, and diarrhea symptoms. The participants' characteristics and reported symptoms are shown in Table 1. Younger patients and patients with minor symptoms/signs (eg, less frequent diarrhea, less bloody stool, and stool with mucus) tended to have difficulty collecting their stool samples. A total of 59 (7.8\%) patients were admitted to the hospital. Antibiotics were given to $76(10.1 \%)$ patients with severe gastroenteritis symptoms in the ED. Median illness duration was 3.0 days (range, 1-55 days). One $(0.1 \%)$ patient with unknown etiology died during admission, and the duration of illness of this dead case was treated as the right censored data (absence of event before study ended) in the accelerated failure time model.

Stool specimens were obtained immediately in 202 patients, and the others were obtained within 24 hours. The mean duration of taking stool specimens (ie, the time between arriving in the ED and obtaining stool specimens) did not differ significantly between the discharge group (mean 15.2 hours) and the admission group (mean 15.3 hours). There was also no difference in the proportion of patients with pathogen findings between the discharge $(63.3 \%)$ and the admission $(63.2 \%)$ groups.

Distributions of microbiologic findings are shown in Table 2. Viruses $(41.4 \%)$ were identified as the leading cause of gastroenteritis, with norovirus $(32.3 \%)$ being the most prevalent. Patients with higher diarrhea frequency $(\geq 6$
Table 1. Characteristics gastroenteritis

of participants with acute

\begin{tabular}{|c|c|c|c|}
\hline Characteristic & $\begin{array}{l}\text { Participants } \\
\text { with stool test } \\
\quad(n=627)\end{array}$ & $\begin{array}{l}\text { Participants } \\
\text { without stool test } \\
\quad(n=127)\end{array}$ & $P^{a}$ \\
\hline \multicolumn{4}{|l|}{ Age, years } \\
\hline Median (range) & $36(15-94)$ & $29(15-88)$ & $<0.001$ \\
\hline \multicolumn{4}{|l|}{ Gender, number (\%) } \\
\hline Male & $286(45.6)$ & $50(39.4)$ & 0.239 \\
\hline Female & $341(54.4)$ & $77(60.6)$ & \\
\hline \multicolumn{4}{|c|}{ Maximum frequency of diarrhea in one day } \\
\hline Median & 6 & 5 & 0.002 \\
\hline Range & $1-50$ & $1-42$ & \\
\hline \multicolumn{4}{|c|}{ Maximum frequency of vomiting in one day } \\
\hline Median & 3 & 3 & 0.401 \\
\hline Range & $1-20$ & $1-10$ & \\
\hline \multicolumn{4}{|c|}{ Symptom distribution, number (\%) } \\
\hline Diarrhea & $533(85.0)$ & $96(75.6)$ & 0.017 \\
\hline Abdominal pain & $366(58.4)$ & $65(51.2)$ & 0.135 \\
\hline Weakness & $297(47.4)$ & $63(49.6)$ & 0.654 \\
\hline Vomiting & $256(40.8)$ & $55(43.3)$ & 0.605 \\
\hline Nausea & $235(37.5)$ & $52(40.9)$ & 0.463 \\
\hline Abdominal bloating & 206 (32.9) & $27(21.3)$ & 0.010 \\
\hline Poor appetite & $187(29.8)$ & $30(23.6)$ & 0.159 \\
\hline Myalgia & 181 (28.9) & $33(26.0)$ & 0.511 \\
\hline Fever & $113(18.0)$ & $19(15.0)$ & 0.408 \\
\hline Tenesmus & $45(7.20)$ & $13(10.2)$ & 0.238 \\
\hline Blood in stool & $31(4.90)$ & $1(0.80)$ & 0.029 \\
\hline Mucus in stool & $126(20.1)$ & $15(11.8)$ & 0.029 \\
\hline
\end{tabular}

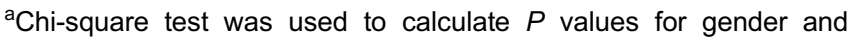
symptom distribution. Wilcoxon rank sum test was used to calculate $P$ value for age, maximum daily diarrheic stool frequency, and maximum daily vomiting frequency. Fisher exact test was used to calculate $P$ values for "Blood in stool".

Table 2. Microbiologic findings among participants

\begin{tabular}{|c|c|c|c|c|}
\hline & $\begin{array}{c}\text { Total } \\
(n=627) \\
\text { Number }(\%)\end{array}$ & $\begin{array}{c}\text { Positive fecal } \\
\text { leukocyte } \\
(n=199) \\
\text { Number (\%) }\end{array}$ & $\begin{array}{c}\text { Positive fecal } \\
\text { hemoccult } \\
(n=258) \\
\text { Number }(\%)\end{array}$ & $\begin{array}{l}\text { Both positive } \\
\quad(n=143) \\
\text { Number }(\%)\end{array}$ \\
\hline Viral pathogens & $259(41.3)$ & $67(33.7)$ & $92(35.7)$ & $42(29.4)$ \\
\hline Norovirus & $202(32.2)$ & $49(24.6)$ & $69(26.7)$ & $31(21.7)$ \\
\hline Rotavirus & $46(7.30)$ & $15(7.50)$ & $18(7.00)$ & $8(5.60)$ \\
\hline Astrovirus & $8(1.30)$ & $3(1.50)$ & $4(1.60)$ & $3(2.10)$ \\
\hline Sapovirus & $7(1.10)$ & $1(0.50)$ & $2(0.80)$ & $1(0.70)$ \\
\hline Adenovirus & $2(0.30)$ & $0(0.00)$ & $1(0.40)$ & $0(0.00)$ \\
\hline Bacterial pathogens & $168(26.8)$ & $76(38.2)$ & $91(35.3)$ & $62(43.4)$ \\
\hline Shigella spp. & $3(0.50)$ & $3(1.50)$ & $3(1.20)$ & $3(2.10)$ \\
\hline Salmonella spp. & $29(4.60)$ & $16(8.00)$ & $19(7.40)$ & $14(9.80)$ \\
\hline Vibrio parahaemolyticus & $34(5.40)$ & $16(8.00)$ & $24(9.30)$ & $14(9.80)$ \\
\hline Aeromonas spp. & $5(0.80)$ & $4(2.00)$ & $4(1.60)$ & $4(2.80)$ \\
\hline Campylobacter spp. & $12(1.90)$ & $7(3.50)$ & $8(3.10)$ & $6(4.20)$ \\
\hline Plesiomonas shigelloides & $2(0.30)$ & $1(0.50)$ & $2(0.80)$ & $1(0.70)$ \\
\hline $\begin{array}{l}\text { Staphylococcus with related } \\
\text { enterotoxin }\end{array}$ & $18(2.90)$ & $5(2.50)$ & $7(2.70)$ & $3(2.10)$ \\
\hline sDEC & $62(9.90)$ & $22(11.1)$ & $22(8.50)$ & $15(10.5)$ \\
\hline Clostridium difficile & $14(2.20)$ & $9(4.50)$ & $9(3.50)$ & $8(5.60)$ \\
\hline Toxigenic Bacteroides fragilis & $8(1.30)$ & $3(1.50)$ & $4(1.60)$ & $2(1.40)$ \\
\hline Pathogenic parasites & $78(12.4)$ & $19(9.50)$ & $29(11.2)$ & $13(9.10)$ \\
\hline Giardia lamblia & $78(12.4)$ & $19(9.50)$ & 29 (11.2) & $13(9.10)$ \\
\hline Unknown pathogens & $230(36.7)$ & $73(36.7)$ & $87(33.7)$ & 49 (34.3) \\
\hline
\end{tabular}

sDEC, Suspected Diarrheagenic E. coli.

${ }^{a} F e c a l$ leukocyte and fecal hemoccult are both positive.

times per day) were more likely to have detected pathogens (68.1\% vs $59.5 \% ; P=0.026)$. Of the 152 patients with blood cultures, $6(3.9 \%)$ were positive for Bacteroides fragilis, E. coli, or Aeromonas salmonicida. The distributions of fecal 
Table 3. Risk factors for gastroenteritis in the matched casecontrol study (612 paired participants)

\begin{tabular}{|c|c|c|c|c|}
\hline \multirow{2}{*}{ Exposure } & \multicolumn{2}{|c|}{ Univariate analysis } & \multicolumn{2}{|c|}{ Multivariate model $^{\mathrm{b}}$} \\
\hline & OR & $95 \% \mathrm{Cl}$ & Adjusted OR & $95 \% \mathrm{Cl}$ \\
\hline $\begin{array}{l}\text { Taking antacids within } 1 \text { month prior } \\
\text { to illness }\end{array}$ & 3.38 & $(2.34,4.88)$ & 4.10 & $(2.57,6.53)$ \\
\hline $\begin{array}{l}\text { Household members/classmates } \\
\text { with gastroenteritis }^{\mathrm{a}}\end{array}$ & 4.64 & $(2.92,7.35)$ & 4.69 & $(2.76,7.96)$ \\
\hline Attending a banquet ${ }^{\mathrm{a}}$ & 2.50 & $(1.91,3.27)$ & 2.29 & $(1.64,3.20)$ \\
\hline Dining out ${ }^{\mathrm{a}}$ & 2.32 & $(1.68,3.20)$ & 1.70 & $(1.13,2.54)$ \\
\hline Eating raw oysters ${ }^{a}$ & 2.82 & $(1.62,4.91)$ & 3.10 & $(1.61,5.94)$ \\
\hline Eating honey peaches ${ }^{a}$ & 1.91 & $(1.14,3.20)$ & - & - \\
\hline Drinking bottled watera & 1.66 & $(1.30,2.12)$ & - & - \\
\hline Eating shrimp/crab ${ }^{\mathrm{a}}$ & 1.45 & $(1.16,1.83)$ & - & - \\
\hline Attending open-air banquet ${ }^{a}$ & 5.33 & $(1.55,18.30)$ & - & - \\
\hline Eating at a Chinese/Western restaurant ${ }^{a}$ & 2.45 & $(1.83,3.28)$ & - & - \\
\hline Eating at street catering ${ }^{a}$ & 2.50 & $(1.35,4.65)$ & - & - \\
\hline Eating at a noodle shop ${ }^{a}$ & 1.35 & $(1.03,1.76)$ & - & - \\
\hline Eating raw fish ${ }^{\mathrm{a}}$ & 1.57 & $(1.16,2.13)$ & - & - \\
\hline $\begin{array}{l}\text { Eating clam/shells } \\
\text { (other than raw oysters) }^{a}\end{array}$ & 1.54 & $(1.21,1.96)$ & - & - \\
\hline Changing a diaper ${ }^{\mathrm{a}}$ & 1.73 & $(1.11,2.72)$ & - & - \\
\hline Eating a cold side dish ${ }^{a}$ & 1.27 & $(0.99,1.63)$ & - & - \\
\hline Eating salad ${ }^{a}$ & 1.19 & $(0.94,1.50)$ & - & - \\
\hline Eating pork ${ }^{\mathrm{a}}$ & 1.17 & $(0.87,1.58)$ & - & - \\
\hline Eating beefa & 1.14 & $(0.89,1.44)$ & - & - \\
\hline
\end{tabular}

$\mathrm{Cl}$, confidence interval; OR, odds ratio.

aExposed to these factors within 1 week prior to illness.

${ }^{b}$ Odds ratio and $95 \%$ confidence interval were derived from conditional logistic regression after stepwise selection.

occult blood and pus cells among different etiologies are listed in Table 2. A high co-infection rate (15.3\%) was noted in this study. Only $26(16.4 \%)$ cases with bacterial gastroenteritis received empirical antibiotics treatment.

\section{Matched case-control study}

Our case-control study sample consisted of 612 matched pairs (267 males and 345 females). Factors significantly associated with gastroenteritis in univariate analysis are shown in Table 3. According to the final multivariate conditional logistic regression analysis, five variables were found to have statistically significant associations with the gastroenteritis cases: taking antacids (adjusted OR 4.10; 95\% CI, 2.57-6.53), having household members/classmates with gastroenteritis (adjusted OR 4.69; 95\% CI, 2.76-7.96), attending a banquet (adjusted OR 2.29; 95\% CI, 1.64-3.20), dining out (adjusted OR 1.70; 95\% CI, 1.13-2.54), and eating raw oysters (adjusted OR 3.10; 95\% CI, 1.61-5.94).

\section{Case-case study}

Our case-case study sample consisted of 627 cases. Significant differences were observed in mean illness duration $(P=$ 0.006), C-reactive protein (CRP) level $(P=0.005)$, presence of fecal leukocyte $(P<0.001)$ and fecal occult blood $(P<0.001)$, and the number of cases with vomiting $(P=$ 0.036 ) among cases of acute gastroenteritis with different etiologies (Appendix eTable 1).

Gastroenteritis patients who were hospitalized were compared to those without hospital admission. The risk factors for hospitalization are shown in Table 4. In the final multivariable logistic regression model, age (adjusted OR
Table 4. Risk factors for admission of patients with acute gastroenteritis to emergency department

\begin{tabular}{|c|c|c|c|c|}
\hline \multirow{2}{*}{ Characteristic } & \multicolumn{2}{|c|}{ Univariable analysis } & \multicolumn{2}{|c|}{ Multivariable analysis } \\
\hline & OR & $(95 \% \mathrm{Cl})$ & OR & $(95 \% \mathrm{Cl})$ \\
\hline Age & 1.04 & $(1.02,1.05)$ & 1.04 & $(1.02,1.05)$ \\
\hline Male gender & 0.79 & $(0.45,1.37)$ & - & - \\
\hline WBC $>10^{4}$ count $/ \mu \mathrm{L}$ & 1.51 & $(0.87,2.65)$ & - & - \\
\hline $\mathrm{CRP}>10 \mathrm{mg} / \mathrm{L}$ & 2.05 & $(1.18,3.56)$ & 2.04 & $(1.15,3.62)$ \\
\hline \multicolumn{5}{|l|}{ Pathogens } \\
\hline Bacteria & 2.21 & $(1.27,3.87)$ & - & - \\
\hline Non-bacteria & 1.00 & & & \\
\hline Fecal pus cell & 3.09 & $(1.78,5.37)$ & 2.04 & $(1.08,3.86)$ \\
\hline Fecal occult blood & 2.69 & $(1.53,4.72)$ & 1.97 & $(1.03,3.77)$ \\
\hline Fever & 1.55 & $(0.82,2.94)$ & - & - \\
\hline Abdomen pain & 1.76 & $(0.98,3.18)$ & & \\
\hline Frequency of vomiting $>5$ times/day & 0.74 & $(0.28,1.91)$ & - & - \\
\hline Frequency of diarrhea $>10$ times/day & 0.92 & $(0.40,2.11)$ & - & - \\
\hline Household members with gastroenteritis & 1.27 & $(0.65,2.50)$ & - & - \\
\hline Taking antacids within 1 month prior to illness & 1.61 & $(0.88,2.94)$ & - & - \\
\hline Eating shrimp/crab & 0.62 & $(0.35,1.08)$ & - & - \\
\hline Eating raw oysters & 0.95 & $(0.28,3.22)$ & - & - \\
\hline
\end{tabular}

$\mathrm{Cl}$, confidence interval; OR, odds ratio.

Table 5. Results from accelerated failure time model for illness duration of patients with acute gastroenteritis

\begin{tabular}{lccccc}
\hline & \multicolumn{2}{c}{ Univariable analysis } & & Multivariable analysis \\
\cline { 2 - 2 } \multicolumn{1}{c}{ Characteristic } & $\begin{array}{c}\text { Time ratio in } \\
\text { illness duration } \\
(95 \% \mathrm{Cl})^{\#}\end{array}$ & $P$ value & & $\begin{array}{c}\text { Time ratio in } \\
\text { illness duration } \\
(95 \% \mathrm{Cl})^{\#}\end{array}$ & $P$ value \\
\hline Age & $1.00(1.00,1.01)$ & 0.497 & - & - \\
Male gender & $0.98(0.84,1.16)$ & 0.846 & - & - \\
Bacterial pathogens & $1.07(0.89,1.28)$ & 0.460 & - & - \\
Fecal leukocyte & $1.22(1.06,1.41)$ & 0.006 & & $1.19(1.06,1.41)$ & 0.014 \\
Frequency of vomiting $>5$ times/day & $0.79(0.64,0.98)$ & 0.028 & & $0.79(0.64,0.97)$ & 0.025 \\
Frequency of diarrhea $>10$ times/day & $0.94(0.77,1.14)$ & 0.525 & & \\
Abdominal pain & $1.23(1.07,1.41)$ & 0.003 & $1.20(1.05,1.38)$ & 0.007 \\
Fever & $1.01(0.85,1.20)$ & 0.950 & & \\
Fecal occult blood & $0.97(0.84,1.11)$ & 0.624 & & \\
\hline
\end{tabular}

$\mathrm{Cl}$, confidence interval.

\#The corresponding regression coefficients in the above models can be obtained by taking the logarithm of time ratio.

1.04; 95\% CI, 1.02-1.05), CRP level $>10 \mathrm{mg} / \mathrm{L}$ (adjusted OR 2.04; 95\% CI, 1.15-3.62), and presence of fecal leukocyte (adjusted OR 2.04; 95\% CI, 1.08-3.86) and fecal occult blood (adjusted OR 1.97; 95\% CI, 1.03-3.77) were found to have statistically significantly associations with hospital admission.

Factors affecting duration of illness of patients with acute gastroenteritis are shown in Table 5. In the univariate analysis of the AFT model, presence of fecal leukocytes (TR 1.22; 95\% CI, 1.06-1.41), abdominal pain (TR 1.23; 95\% CI, $1.07-1.41$ ), and frequency of vomiting ( $>5$ times/day; TR 0.79 ; $95 \%$ CI, 0.64-0.98) were significantly associated with the duration of illness. Presence of fecal leukocytes (TR 1.19; 95\% CI, 1.06-1.41), abdominal pain (TR 1.20; 95\% CI, $1.05-1.38$ ), and frequency of vomiting (TR $0.79 ; 95 \% \mathrm{CI}$, $0.64-0.97)$ remained statistically significant in the multivariable model.

Factors significantly associated with bacterial gastroenteritis based on univariate analysis are presented in Table 6. According to our results from the final multivariable logistic analysis, four variables were found to 
Table 6. Risk factors for bacterial gastroenteritis comparing with non-bacterial gastroenteritis

\begin{tabular}{|c|c|c|c|c|c|}
\hline \multirow{2}{*}{\multicolumn{2}{|c|}{ Factors }} & \multicolumn{2}{|c|}{ Univariable analysis } & \multicolumn{2}{|c|}{ Multivariable analysis } \\
\hline & & OR & $95 \% \mathrm{Cl}$ & Adjusted OR & $95 \% \mathrm{Cl}$ \\
\hline \multicolumn{2}{|l|}{ Age } & 1.01 & $(1.00,1.01)$ & - & - \\
\hline \multicolumn{2}{|c|}{ Male gender } & 0.93 & $(0.65,1.33)$ & - & - \\
\hline \multicolumn{2}{|c|}{ WBC $>10^{4}$ count $/ \mu \mathrm{L}$} & 1.35 & $(0.94,1.93)$ & - & - \\
\hline \multicolumn{2}{|c|}{$\mathrm{CRP}>10 \mathrm{mg} / \mathrm{L}$} & 1.45 & $(1.01,2.07)$ & - & - \\
\hline \multicolumn{2}{|c|}{ Fecal leukocyte } & 2.19 & $(1.52,3.17)$ & 2.08 & $(1.42,3.05)$ \\
\hline \multicolumn{2}{|c|}{ Fecal occult blood } & 1.96 & $(1.37,2.81)$ & - & - \\
\hline \multicolumn{2}{|c|}{ Abdomen pain } & 1.10 & $(0.76,1.57)$ & & \\
\hline \multicolumn{2}{|c|}{ Fever } & 1.40 & $(0.90,2.17)$ & - & - \\
\hline \multicolumn{2}{|c|}{ Shock (systolic blood pressure } & 1.08 & $(0.38,3.08)$ & - & - \\
\hline \multicolumn{2}{|c|}{ Frequency of vomiting $>5$ times/day } & 0.48 & $(0.25,0.93)$ & 0.54 & $(0.27,1.08)$ \\
\hline \multicolumn{2}{|c|}{ Frequency of diarrhea $>10$ times/day } & 1.75 & $(1.07,2.86)$ & 1.69 & $(1.01,2.83)$ \\
\hline \multirow[t]{3}{*}{ Season } & Summer & 1.51 & $(0.99,2.32)$ & 1.54 & $(0.99,2.40)$ \\
\hline & Winter & 0.39 & $(0.24,0.63)$ & 0.45 & $(0.28,0.74)$ \\
\hline & Spring and Autumn & 1.00 & - & 1.00 & - \\
\hline \multicolumn{2}{|c|}{ Eating shrimp/crab } & 1.46 & $(1.02,2.09)$ & 1.53 & $(1.05,2.23)$ \\
\hline \multicolumn{2}{|c|}{ Eating raw fish } & 1.53 & $(1.00,2.36)$ & & \\
\hline \multicolumn{2}{|c|}{$\begin{array}{l}\text { Taking antacids within } 1 \text { month prior to } \\
\text { illness }\end{array}$} & 1.57 & $(0.76,3.25)$ & & \\
\hline \multicolumn{2}{|c|}{$\begin{array}{l}\text { Household members with } \\
\text { gastroenteritis }\end{array}$} & 1.30 & $(0.83,2.03)$ & & \\
\hline \multicolumn{2}{|c|}{ Eating raw oysters } & 1.19 & $(0.58,2.47)$ & & \\
\hline
\end{tabular}

$\mathrm{Cl}$, confidence interval; OR, odds ratio.

have statistically significant associations with the bacterial gastroenteritis cases: presence of fecal leukocytes (adjusted OR 2.08; 95\% CI, 1.42-3.05), winter (adjusted OR 0.45; 95\% CI, 0.28-0.78), frequency of diarrhea $>10$ times/day (adjusted OR 1.69; 95\% CI, 1.01-2.83), and eating shrimp or crab (adjusted OR 1.53; 95\% CI, 1.05-2.23).
The sensitivity, specificity, and positive and negative predictive values of the presence of fecal leukocytes as a predictor of bacterial gastroenteritis were $44.9 \%, 72.9 \%$, $37.2 \%$, and $78.7 \%$, respectively. The sensitivity, specificity, and positive and negative predictive values of the presence of fecal occult blood as a predictor of bacterial gastroenteritis were $53.3 \%, 63.2 \%, 34.1 \%$, and $79.1 \%$, respectively. Respective accuracy measures of CRP level $(>10 \mathrm{mg} / \mathrm{L})$ as a predictor of bacterial gastroenteritis were $48.5 \%, 60.6 \%$, $30.5 \%$, and $76.7 \%$. The ROC curve for CRP level (>10 mg/L), presence of fecal occult blood, presence of fecal leukocytes, and the composite of factors included in our final model (presence of fecal leukocytes, frequency of diarrhea $>10$ times/day, frequency of vomiting $>5$ times/day, season, and eating shrimp or crab) is shown in Figure. The respective AUROCs were 0.55 (95\% CI, 0.50-0.59), 0.58 (95\% CI, $0.54-0.63), 0.59$ (95\% CI, 0.55-0.63) and 0.68 (95\% CI, $0.55-0.63)$. The positive and negative predictive values of our final model were $60.0 \%$ and $75.4 \%$, respectively.

\section{DISCUSSION}

The current study assesses many aspects, including the etiology and risk factors of gastroenteritis in adolescents and adults, as well as factors affecting the odds for admission, the duration of illness, and ancillary testing for bacterial gastroenteritis in the ED. We found that viral infection was the leading cause of gastroenteritis and tends to cause gastroenteritis in winter. Older age, elevated CRP level, presence of fecal leukocytes, and presence of fecal occult

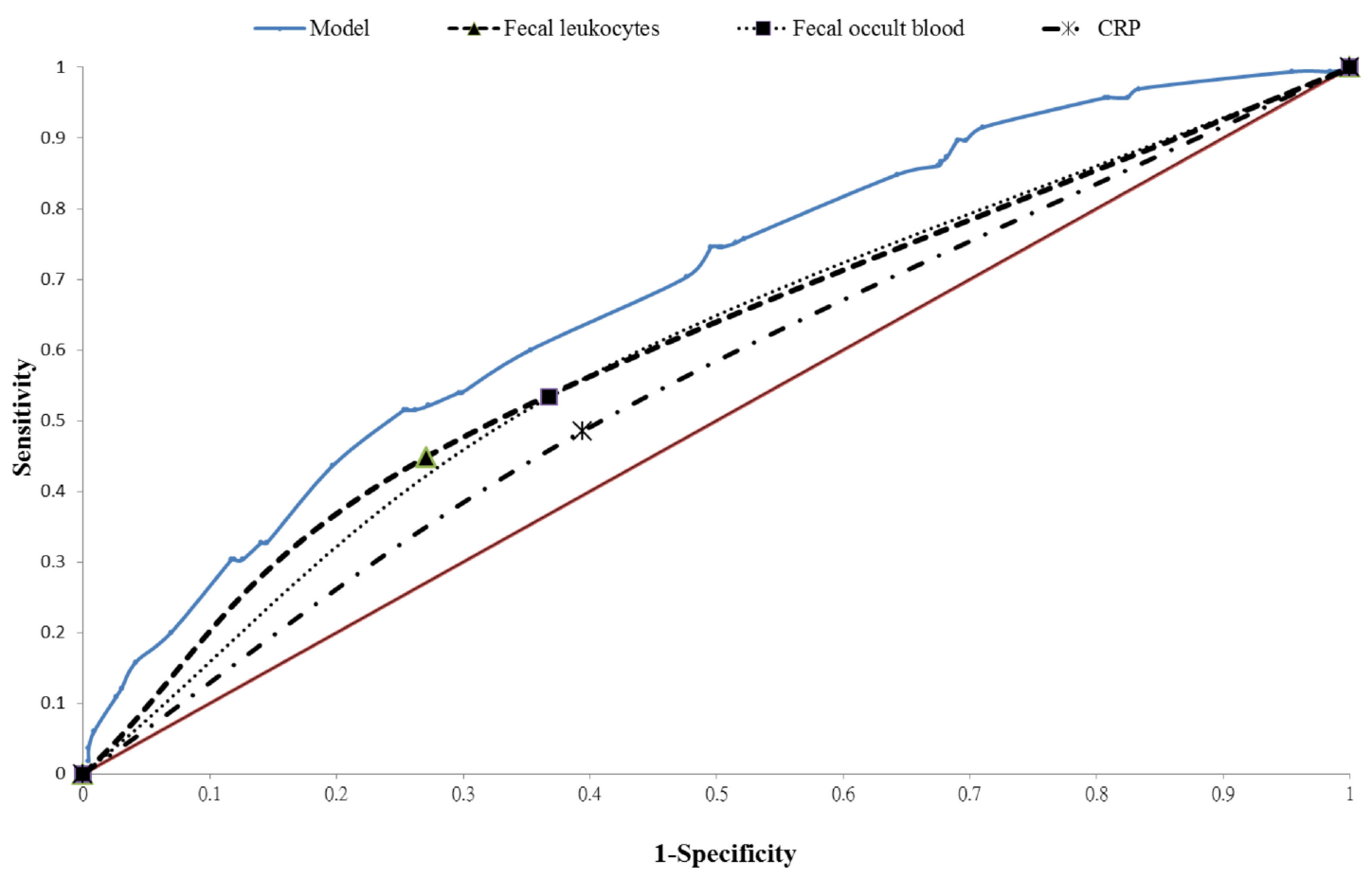

Figure. Receiver operating characteristic (ROC) curve for the ancillary test. The area under the ROC curve is 0.681 for our model, 0.589 for fecal leukocytes, 0.583 for fecal occult blood, and 0.546 for CRP (>10 mg/L). 
blood were significantly associated with hospital admission. In addition, presence of fecal leukocytes, frequency of vomiting, and abdominal pain were significantly associated with the duration of illness. Presence of fecal leukocytes, winter, frequency of diarrhea $>10$ times/day, and eating shrimp or crab were highly associated with bacterial gastroenteritis. The presence of fecal leukocytes or fecal occult blood and elevated CRP level ( $>10 \mathrm{mg} / \mathrm{L})$ have low sensitivity and specificity for predicting bacterial gastroenteritis. The AUROC of elevated CRP level, presence of fecal occult blood, presence of fecal leukocytes, and presence of all risk factors included in our final model were $0.546,0.583,0.589$, and 0.681 , respectively.

Our finding that norovirus was the leading cause of gastroenteritis cases in both adolescents and adults agrees with previous reports. ${ }^{1,7-10}$ Clostridium difficile was not thought to be a dominant pathogen for community-acquired diarrhea until Huhulescu et al proved it. ${ }^{7}$ However, community-acquired Clostridium difficile is still not a great problem in Taipei: it was identified in only $2.2 \%$ of all cases in our study. About $15.3 \%$ of patients were diagnosed with coinfection with bacteria and other non-bacterial pathogens; the relatively high detection rate of non-bacterial pathogens was due to our use of PCR to detect norovirus, giardia, B. fragilis, and $C$. difficile. The majority of co-infected patients were co-infected with norovirus and other pathogens. It should be noted that norovirus may not be the cause of illness in all cases that were positive for norovirus because healthy people can deliver false-positive results on PCR. ${ }^{11}$ We also observed a higher pathogen detection rate for patients with 6 or more daily episodes of diarrhea, which was similar to the results of a previous study. ${ }^{12}$

About $36.7 \%$ of gastroenteritis cases in our study were unexplained. Picobirnavirus may account for a proportion of these unknown cases, according to recent studies. ${ }^{13,14}$ Further studies are needed to clarify the possible pathogenicity of unexplained gastroenteritis.

Our findings about the risk factors of gastroenteritis are similar to previous studies. Dining out (defined as eating anywhere away from one's home) was found to be associated with food poisoning cases at the ED in previous studies. ${ }^{1,15}$ Attending a banquet has also been associated with outbreaks of gastroenteritis. ${ }^{1,16}$ Decreasing gastric acidity is a risk factor for infectious diarrhea-related illnesses ${ }^{1,17}$ because gastric acid is capable of killing ingested bacteria. ${ }^{18}$ Household transmission is a known risk factor for gastroenteritis. ${ }^{1,19-21}$ Eating raw oysters has also been shown to increase the risk of gastroenteritis. ${ }^{1,22-25}$

Most gastroenteritis tends to be self-limiting and requires only supportive therapy. Antibiotic treatment is suggested in patients with a suspected invasive process and severe diarrhea, systemic symptoms, fever, or abdominal pain, as well as in patients who show toxic signs. ${ }^{3}$ However, fever and abdominal pain were not predictors of bacterial diarrhea in the present study. Further, eating shrimp or crab has been reported to be associated with diarrheagenic E. coli, ${ }^{26}$ Vibrio spp., ${ }^{27-29}$ Aeromonas spp., ${ }^{30}$ and Listeria monocytogenes ${ }^{31}$ infection in previous studies. Eating shrimp or crab was a predictor of bacterial gastroenteritis in the present study. Diarrhea in winter tends to be viral gastroenteritis because norovirus and rotavirus spread more easily in winter than in other seasons.

Though the presence of fecal leukocytes or fecal occult blood had low power for prediction of bacterial gastroenteritis, they were highly associated with hospital admission, and patients with fecal leukocytes were also found to have longer duration of illness than those without fecal leukocytes. However, patients with higher frequency of vomiting were found to have shorter duration of illness because such symptoms tended to result from viral gastroenteritis and no severe dehydration.

The sensitivity and specificity of microscopy for fecal leukocytes was heterogeneous in previous studies. ${ }^{32}$ No consistent trend in the test threshold (cells per HPF) to any of the diagnostic parameters has been observed. Our study demonstrated that the AUROC of bacterial gastroenteritis prediction was elevated after adding other predictors (winter, frequency of vomiting, frequency of diarrhea, and eating shrimp or crab) to the ED. The epidemiological evidence and clinical evidence were associated with the probability of "not norovirus" from as low as $8 \%$ to as high as $100 \%{ }^{2}$ However, there are still no ancillary tests or good models to predict bacterial gastroenteritis, and the guidelines for antimicrobial treatment of acute gastroenteritis are also ambiguous. One study reported that body temperature, abdominal pain, leukocyte count in stool, and poor dietary hygiene can be used as predictors of acute bacterial diarrhea in hospitalized patients. ${ }^{33}$ The AUROC was 0.975 (95\% CI, 0.962-0.987) in their study. As acute bacterial diarrhea is also highly dependent on the environments in which patients live, the AUROC result may vary from study to study. The diagnostic accuracy of bacterial gastroenteritis using our model was not good enough due to the high percentage of cases with unknown etiology and co-infection with viruses in our study group. Further studies on the prediction of non-viral or bacterial gastroenteritis using the Bayesian approach should be considered.

The case-case comparison is more efficient and less biased than standard case-control studies for determining exposure to infectious agents, but general factors that are responsible for whether acute gastroenteritis occurs after the exposure cannot be studied. ${ }^{34}$ Selection bias may result from the low response rate of the ED cases. Greater frequency of diarrhea was noted in enrolled cases compared to in non-participators, ${ }^{1}$ and younger patients and patients with minor symptoms/signs were less likely to provide stool samples. In addition, patients with longer duration of gastroenteritis were more likely to visit the ED (ie, length bias) than those with shorter duration of illness. However, selection bias was minimized in this 
study by adjusting for these factors, including the frequency of diarrhea, age, and duration of gastroenteritis, when they were measured in all study subjects. Our findings tend to overestimate the positive detection rate of diarrheagenic E. coli using the $\mathrm{O}$ serotyping method alone. ${ }^{35}$

In summary, taking antacids, having household members/ classmates with gastroenteritis, attending a banquet, dining out, and eating raw oysters were highly associated with gastroenteritis. The elderly and those with elevated CRP levels and the presence of fecal leukocytes and fecal occult blood tended to be hospitalized in the ED. The presence of fecal leukocytes, winter, frequent diarrhea, and eating shrimp or crab were highly associated with bacterial gastroenteritis.

\section{ONLINE ONLY MATERIALS}

eTable 1. Characteristics of participants with acute gastroenteritis in different etiologic groups.

eQuestionnaire. Questionnaire of Gastroenteritis Investigation.

\section{ACKNOWLEDGMENTS}

The authors wish to thank the ED staff of Taipei City Hospital (Ren-Ai) for their help in data collection.

Funding: The study was supported by the Taiwan Centers for Disease Control grant and the Taipei City Health Department grant.

Conflicts of interest: None declared.

\section{REFERENCES}

1. Lai CC, Wu FT, Ji DD, Mu JJ, Yang JR, Chiu KT, et al. Gastroenteritis in a Taipei emergency department: aetiology and risk factors. Clin Microbiol Infect. 2011;17:1071-7.

2. Goodgame R. A Bayesian approach to acute infectious diarrhea in adults. Gastroenterol Clin North Am. 2006;35:249-73.

3. Marx J, Hockberger R, Walls R. Rosen's Emergency Medicine-Concepts and Clinical Practice 8th ed. Philadelphia, PA: Elsevier/Saunders; c2014.

4. Ji D, Huang IH, Lai CC, Wu FT, Jiang DD, Hsu BM, et al. Prevalence and characterization of enterotoxigenic Bacteroides fragilis and toxigenic Clostridium difficile in a Taipei emergency department. J Microbiol Immunol Infect. 2014.

5. Bradburn MJ, Clark TG, Love SB, Altman DG. Survival analysis part II: multivariate data analysis - an introduction to concepts and methods. Br J Cancer. 2003;89:431-6.

6. Hanley JA, McNeil BJ. The meaning and use of the area under a receiver operating characteristic (ROC) curve. Radiology. 1982;143:29-36.

7. Huhulescu S, Kiss R, Brettlecker M, Cerny RJ, Hess C, Wewalka $\mathrm{G}$, et al. Etiology of acute gastroenteritis in three sentinel general practices, Austria 2007. Infection. 2009;37:103-8.

8. Amar CF, East CL, Gray J, Iturriza-Gomara M, Maclure EA, McLauchlin J. Detection by PCR of eight groups of enteric pathogens in 4627 faecal samples: re-examination of the English case-control Infectious Intestinal Disease Study (1993-1996). Eur J Clin Microbiol Infect Dis. 2007;26:311-23.

9. Alain S, Denis F. [Epidemiology of infectious acute diarrhoea in France and Europe]. Arch Pediatr. 2007;14 Suppl 3:S132-44.

10. Phillips G, Tam CC, Conti S, Rodrigues LC, Brown D, IturrizaGomara M, et al. Community incidence of norovirus-associated infectious intestinal disease in England: improved estimates using viral load for norovirus diagnosis. Am J Epidemiol. 2010;171:1014-22.

11. Phillips G, Lopman B, Tam CC, Iturriza-Gomara M, Brown D, Gray J. Diagnosing norovirus-associated infectious intestinal disease using viral load. BMC Infect Dis. 2009;9:63.

12. Barreto ML, Milroy CA, Strina A, Prado MS, Leite JP, Ramos EA, et al. Community-based monitoring of diarrhea in urban Brazilian children: incidence and associated pathogens. Trans $\mathrm{R}$ Soc Trop Med Hyg. 2006;100:234-42.

13. van Leeuwen M, Williams MM, Koraka P, Simon JH, Smits SL, Osterhaus AD. Human picobirnaviruses identified by molecular screening of diarrhea samples. J Clin Microbiol. 2010;48: 1787-94.

14. Moore NE, Wang J, Hewitt J, Croucher D, Williamson DA, Paine $\mathrm{S}$, et al. Metagenomic analysis of viruses in feces from unsolved outbreaks of gastroenteritis in humans. J Clin Microbiol. 2015;53:15-21.

15. Leman P, Strachan D. A case-control study of food poisoning seen at an accident and emergency department. Lancet. 2001; 358:387-8.

16. From the Centers for Disease Control and Prevention. Foodborne outbreak of Cryptosporidiosis-Spokane, Washington, 1997. JAMA. 1998;280(7):595-6.

17. Leonard J, Marshall JK, Moayyedi P. Systematic review of the risk of enteric infection in patients taking acid suppression. Am J Gastroenterol. 2007;102:2047-56; quiz 2057.

18. Williams C. Occurrence and significance of gastric colonization during acid-inhibitory therapy. Best Pract Res Clin Gastroenterol. 2001;15:511-21.

19. Perry S, de la Luz Sanchez M, Hurst PK, Parsonnet J. Household transmission of gastroenteritis. Emerg Infect Dis. 2005;11: 1093-6.

20. Leder K, Sinclair M, Forbes A, Wain D. Household clustering of gastroenteritis. Epidemiol Infect. 2009;137:1705-12.

21. Siddiqui FJ, Bhutto NS, von Seidlein L, Khurram I, Rasool S, Ali M, et al. Consecutive outbreaks of Vibrio cholerae O139 and V. cholerae O1 cholera in a fishing village near Karachi, Pakistan. Trans R Soc Trop Med Hyg. 2006;100:476-82.

22. Carnahan AM, Harding J, Watsky D, Hansman S. Identification of Vibrio hollisae associated with severe gastroenteritis after consumption of raw oysters. J Clin Microbiol. 1994;32:1805-6.

23. Reeve G, Martin DL, Pappas J, Thompson RE, Greene KD. An outbreak of shigellosis associated with the consumption of raw oysters. N Engl J Med. 1989;321:224-7.

24. Wilson R, Lieb S, Roberts A, Stryker S, Janowski H, Gunn R, et al. Non-O group 1 Vibrio cholerae gastroenteritis associated with eating raw oysters. Am J Epidemiol. 1981;114:293-8.

25. Tsai GJ, Chen TH. Incidence and toxigenicity of Aeromonas hydrophila in seafood. Int J Food Microbiol. 1996;31:121-31.

26. Jain S, Chen L, Dechet A, Hertz AT, Brus DL, Hanley K, et al. 
An outbreak of enterotoxigenic Escherichia coli associated with sushi restaurants in Nevada, 2004. Clin Infect Dis. 2008; 47:1-7.

27. Velazquez-Roman J, León-Sicairos N, Flores-Villaseñor H, Villafaña-Rauda S, Canizalez-Roman A. Association of pandemic Vibrio parahaemolyticus O3:K6 present in the coastal environment of Northwest Mexico with cases of recurrent diarrhea between 2004 and 2010. Appl Environ Microbiol. 2012;78:1794-803.

28. Lim-Quizon MC, Benabaye RM, White FM, Dayrit MM, White ME. Cholera in metropolitan Manila: foodborne transmission via street vendors. Bull World Health Organ. 1994;72:745-9.

29. Finelli L, Swerdlow D, Mertz K, Ragazzoni H, Spitalny K. Outbreak of cholera associated with crab brought from an area with epidemic disease. J Infect Dis. 1992;166:1433-5.

30. Hänninen ML, Oivanen P, Hirvelä-Koski V. Aeromonas species in fish, fish-eggs, shrimp and freshwater. Int J Food Microbiol. 1997;34:17-26.
31. Riedo FX, Pinner RW, Tosca ML, Cartter ML, Graves LM, Reeves MW, et al. A point-source foodborne listeriosis outbreak: documented incubation period and possible mild illness. J Infect Dis. 1994;170:693-6.

32. Gill CJ, Lau J, Gorbach SL, Hamer DH. Diagnostic accuracy of stool assays for inflammatory bacterial gastroenteritis in developed and resource-poor countries. Clin Infect Dis. 2003;37:365-75.

33. Wang Y, Zhang TP, Xiao HL, Qi HY, Yin CH. Formulation of an early warning infectivity score system for adult patients with acute bacterial diarrhea. Biomed Environ Sci. 2014;27:65-9.

34. McCarthy N, Giesecke J. Case-case comparisons to study causation of common infectious diseases. Int $\mathrm{J}$ Epidemiol. 1999;28:764-8.

35. Yang JR, Wu FT, Tsai JL, Mu JJ, Lin LF, Chen KL, et al. Comparison between $\mathrm{O}$ serotyping method and multiplex realtime PCR to identify diarrheagenic Escherichia coli in Taiwan. J Clin Microbiol. 2007;45:3620-5. 